\title{
Evaluation of changes in perfusion defect and left ventricular systolic function using Tc-99m Tetrofosmin single photon emission computed tomography over 3 month period in patients of Acute Myocardial Infarction undergoing primary angioplasty
}

AVS Anil Kumar ${ }^{1}$, PG Kumar ${ }^{1}$, Ajay Swami², Yateendra Dinker ${ }^{3}$

${ }^{1}$ Department of Nuclear Medicine Command Hospital (SC) Pune, Maharashtra, India

${ }^{2}$ Army Hospital Research and Referral New Delhi India

${ }^{3} \mathrm{No}^{-6}$ Air force Hospital, Coimbatore, Tamil Nadu India

[Received 24 XI 2016; Accepted 2 VIII 2017]

Study conducted at Command Hospital Air force Bangalore India.

\begin{abstract}
BACKGROUND. After a primary transluminal coronary angioplasty (PTCA) following AMI (acute myocardial infarction), the perfusion defect and LV (left ventricular) function recover/change over a period of time. The analysis immediately after the procedure may not be true depiction of the exact success of the procedure. There is varying and scanty information available on the natural course of changes in these parameters after a successful PTCA. We hypothesized that majority of change occurs at 3-4 month period. Hence, we undertook this study on the natural course of recovery/changes occurring in perfusion defect size and LV function in first 3 months after primary angioplasty.

MATERIAL AND METHODS. 30 consecutive cases of first AMI who were taken up for Primary angioplasty were enrolled into the study. Resting MPI (Myocardial perfusion imaging) was done within 24-72 hrs of admission using Tc-99m-Tetrofosmin and after 10-14 weeks. Analysis of LVEF (left ventricular ejection fraction), summed segmental score and extent of perfusion defect was done. Images were processed using autocardiac software of emory tool box and quantification was done using QPS (quantitative perfusion SPECT) and QGS (qualitative perfusion SPECT) softwares. 20 segment scoring method was used for quantification on bull's eye images. Student $t$ test (two tailed, dependent) was used to find the significance of study parameters on continuous scale within each group. Effect size was computed to find the effect. Pearson correlation between perfusion defect and LVEF was performed at acute stage and after 10-14 weeks.

RESULTS. The average acute perfusion defect extent was $19.76 \pm 12.89 \%$ which after 3 months became $16.79 \pm 12.61 \%$. The summed segmental score changed from $14.31 \pm 10.58$ to $11.38 \pm 10.03$ and LVEF improved from $48.40 \pm 13.15 \%$ to 53.37 $\pm 12.8 \%$. There was significant improvement in LVEF from acute setting to $10-14$ weeks $(p=0.001)$. There was significant lowering of summed score $(p=0.007)$. Perfusion defect size showed significant reduction $(p=0.030)$. Three patients showed deterioration in perfusion defect size and in summed score with reduction in LVEF. Four patients had no change in any of the parameters. Correlation between perfusion defect and LVEF was strong both at baseline $(r=-0.705, p<0.001)$ and after $10-18$ weeks $(r=-0.766, p<0.001)$.

CONCLUSION. The changes we found in 3 months are similar to earlier studies and also to studies using follow up at 6 months to 1 year. We feel that 3 months is a good enough time to accurately assess the success of primary angioplasty.
\end{abstract}

KEY words: primary angioplasty, tetrofosmin, myocardial perfusion imaging, left ventricular ejection fraction

Nucl Med Rev 2018; 21, 1: 1-7 


\section{Introduction}

Restoration of epicardial blood flow after revascularization may not be equivalent to restoration of complete myocardial blood flow. The microvascular flow also determines the outcome and this flow depends on various factors e.g. presence of any microemboli during the angioplasty, inflammation and edema of the myocardium due to the primary event or prolonged dilatation of vessels impairing autoregulation [1]. The perfusion may recover over months. Hence it takes time for full recovery to be seen after revascularization. Moreover, after the myocardial salvage post revascularization, part of the salvaged segment may still be stunned. Stunned myocardium is viable myocardium salvaged by coronary reperfusion that exhibits prolonged postischemic dysfunction after reperfusion [2]. It could also be due to intermittently reduced blood flow. In addition there might have been some hibernating myocardium present prior to the revascularization procedure. Hibernating myocardium is ischemic myocardium supplied by a narrowed coronary artery in which ischemic cells remain viable but contraction is chronically depressed. This can be reversed by restoring the oxygen supply [3]. Persistent ischemic dysfunction leads to hibernation. The restoration of the full contractile function after the revascularization procedure occurs over a period of time. Hence, the functional state of LV (left ventricle) and wall motion abnormalities immediately after the revascularization may not be true depiction of the exact success of the procedure.

Hence, we need to monitor the patient's status after successful revascularization with methods which evaluate the myocardial perfusion and LV function not only within few days but also after few months of the salvage procedure to accurately assess the success of the procedure. However, patient is curious to know the exact improvement/success of the procedure. How early can we provide them with this information and accurately prognosticate the condition and what is the natural course of changes in perfusion and function after successful revascularization are important questions to be answered. The perfusion in the distribution of dilated artery has been shown to improve progressively until 3 months [4]. Many authors have not found any difference in LV ejection fraction values in the third and sixth month following AMI [5-7]. This makes us hypothesize that majority of the improvement occurs in the first 3-4 months. The aim of this study is to evaluate the changes occurring in perfusion defect size and LV function in the first 3 months after primary angioplasty. The second aim is to assess whether 3 months period is good enough to accurately evaluate the results of reperfusion.

\section{Material and methods}

\section{Study population}

Inclusion criteria - patients who were admitted for the first time with AMI to coronary care unit in Command hospital Bangalore within 12 hours of onset of chest pain and who were taken up for primary angioplasty were enrolled into the study. The study duration for 30 patients was 18 months. Each patient was observed for total duration of 10-14 weeks. Diagnosis of AMI was based on clinical criteria, ST segment elevation and angiographically demonstrated epicardial artery occlusion. All the vessels involved were stented with drug eluting stent. The average time from onset to reperfusion was 3-4 hours. Two patients were ballooned at 8 hours and one at 7 hours of onset of symptoms. As our centre has a fully functional $24 \times 7$ cardiac catheterization lab, all the patients admitted with AMI and suitable for thrombolysis with lesions suitable for angioplasty as recommended in the standard guidelines [8] are treated by primary angioplasty.

Exclusion criteria for this study were pregnancy, history of any previous percutaneous intervention, those who had undergone coronary artery bypass grafting (CABG), history of any previous $\mathrm{MI}$ and patients who during the 3-month review were detected to have restenosis or new lesions on angiography (angiography was done as per cardiologists opinion - either based on symptoms of patients or detected to have positive stress test).

The 30 patients who met the above criteria were included in the study. Resting myocardial perfusion imaging (MPI) was done within 24-72 hours after angioplasty and repeat MPI was done after 10-14 weeks of angioplasty. The treatment following angioplasty was not randomized. The patients were treated as per the decision of cardiology team.

\section{MPI protocol}

MPI was done using Siemens dual headed single photon emission computed tomography (SPECT) gamma camera (E-cam Seimens medical solution, health services, Erlangen, Germany). Gated SPECT at rest was done 40 minutes after injection of $10 \mathrm{mci}$ of Tc-99m Tetrofosmin (Myoview GE healthcare, Buckinghamshire, UK). Low energy high resolution collimator (LEHR), with the 2 detectors configured at 76 degrees, were used with step and shoot with 32 views, 30 seconds per projection, gating synchronization with R wave, 8 frames per cardiac cycle, energy window $20 \%$ over $140 \mathrm{Kev}$ photopeak, 64 × 64 matrix and patient in supine position. Reconstruction was performed with filtered back projection method using Butterworth filter. Images were further processed using auto cardiac software of Emory Tool Box and quantitative parameters and scoring was done using QPS (quantitative perfusion SPECT) and QGS (quantitative gated SPECT) softwares of cedars cardiac quantification with e-soft Jan 2002. Percentage of defect was calculated using the software. 20 segment scoring method was used for quantification on polar maps in relation to the activity distribution in healthy, gender-stratified, reference populations for the same LV region. The segments were scored on a 5 point scale [9]. 0 - normal perfusion; 1 - mild perfusion defect; 2 - moderate defect; 3 - severe defect and 4 - no perfusion. LVEF was calculated by gated SPECT using QGS soft ware. All the imaging was done by the same team with the same machine and application.

\section{Statistical analysis}

Statistical methods: Descriptive statistical analysis has been carried out in the study. Results on continuous measurements are presented on Mean \pm SD (Min-Max) and results on categorical measurements are presented in number (\%). Significance is assessed at $5 \%$ level of significance. Student t test (two tailed, dependent) was used to find the significance of study parameters on continuous scale within each group. Effect size has been computed to find the effect. Pearson correlation between extent and LVEF (Left Ventricular Ejection Fraction) has been performed at acute stage and after 3 months. 
Clearance from ethical committee of Command hospital of Rajiv Gandhi university of health sciences Bangalore and written informed consent for the patients were obtained for the study.

$\begin{array}{ll}\text { Classification of Correlation Co-efficient }(r) \\ \text { Up to } 0.1 & \text { Trivial Correlation } \\ 0.1-0.3 & \text { Small Correlation } \\ 0.3-0.5 & \text { Moderate Correlation } \\ 0.5-0.7 & \text { Large Correlation } \\ 0.7-0.9 & \text { V. Large Correlation } \\ 0.9-1.0 & \text { Nearly Perfect correlation } \\ 1 & \text { Perfect correlation }\end{array}$

\section{Significant figures}

+ Suggestive significance ( $p$ value: $0.05<p<0.10$ )

* Moderately significant ( $p$ value:0.01 $<p \leq 0.05)$

** Strongly significant ( $p$ value: $p \leq 0.01$ )

Statistical software: The Statistical software namely SAS 9.2, SPSS 15.0, Stata 10.1, MedCalc 9.0.1, Systat 12.0 and R environment ver.2.11.1 were used for the analysis of the data and Microsoft word and Excel have been used to generate graphs, tables.

\section{Results}

The demographic characteristics of the 30 patients are as shown in Table 1. There were 27 males and 3 females, majority (66.7\%) were in age group of 40 to $60.60 \%$ of patients were hypertensive, $50 \%$ were smokers and $30 \%$ had type-2 diabetes mellitus. Out of the total 30 cases, $66.7 \%$ patients $(n=20)$ suffered from anterior wall MI (AWMI), 2\% ( $n=2)$ antero-septal wall MI (ASWMI), one case had inferolateral wall $\mathrm{Ml}$ and $23.3 \%$ patients $(n=7)$ had inferior wall MI (IWMI) (Table 2). 23 patients had single vessel disease - 18 left anterior descending artery (LAD), 4 right coronary artery (RCA) and 1 left circumflex artery (LCX). 7 patients had double vessel disease (Table 3). 29 cases achieved Thrombolysis in Myocardial Infarction Trial-3 (TIMI-3) flow and in one case TIMI-2 flow was achieved. The average time to reperfusion was 3-4 hours (Table 4). Two patients were revascularized at 8 hours and 1 at 7 hours of onset

Table 1. Demographic data

\begin{tabular}{lc}
\hline VARIABLE & $n$ or mean \\
\hline Age & $50.07 \pm 10.01$ \\
Men & $27(90 \%)$ \\
Smokers & $15(50 \%) \mathrm{F}-0$ \\
Hypertension & $18(60 \%) \mathrm{F}-3$ \\
Diabetes & $09(30 \%) \mathrm{F}-2$ \\
Previous CABG & 0 \\
Previous angina & $03(10 \%) \mathrm{F}-0$ \\
Time of reperfusion (hours) & $5(16.7 \%)$ \\
$1-2$ & $13(43.3 \%) \mathrm{F}-1$ \\
$3-4$ & $9(30 \%) \mathrm{F}-1$ \\
$5-6$ & $3(10 \%) \mathrm{F}-1$ \\
$7-8$ &
\end{tabular}

Table 2. Infarct region

\begin{tabular}{lcc}
\hline Diagnosis & $\begin{array}{c}\text { Number of patients } \\
(\mathrm{n}=\mathbf{3 0})\end{array}$ & $\%$ \\
\hline ASWMI & 2 & 6.6 \\
AWMI & 20 & 66.7 \\
INFEROLAT MI & 1 & 3.3 \\
IWMI & 7 & 23.3 \\
ASWMI - antero-septal wall myocardial infarction; AWMI — anterior wall myocardial \\
infarction; INFEROLAT MI - inferolateral wall myocardial infarction; IWMI - inferior wall \\
myocardial infarction
\end{tabular}

Table 3. Culprit Vessel

\begin{tabular}{lcc} 
Artery & $\begin{array}{c}\text { Number of patients } \\
(\mathbf{n}=\mathbf{3 0})\end{array}$ & $\%$ \\
\hline LAD & 18 & 60.0 \\
LAD/LCX & 2 & 6.7 \\
LAD/RCA & 1 & 3.3 \\
LCX & 1 & 3.3 \\
LCX/LAD & 1 & 3.3 \\
RCA & 4 & 13.3 \\
RCA/LAD & 1 & 3.3 \\
RCA/LCX & 2 & 6.7 \\
LAD - left anterior descending; LCX - left circumflex; RCA - right coronary artery
\end{tabular}

Table 4. Time to reperfusion in hours

\begin{tabular}{|lcc|}
$\begin{array}{l}\text { Time to reperfusion } \\
\text { (hr) }\end{array}$ & $\begin{array}{c}\text { Number of patients } \\
(\mathbf{n}=\mathbf{3 0})\end{array}$ \\
\hline $1-2$ & 5 & 16.7 \\
$3-4$ & 13 & 43.3 \\
$5-6$ & 9 & 30.0 \\
$7-8$ & 3 & 10.0 \\
\hline
\end{tabular}

of symptoms. Analysis of LVEF, summed rest score (SRS) and extent of perfusion defect in acute setting and after 10-14 weeks was done (Table 5 and Fig. 1, 2 and 3). The average acute perfusion defect extent in the whole group was $19.76 \pm 12.89 \%$ which after 3 months became $16.79 \pm 12.61 \%$. The summed segmental score changed from $14.31 \pm 10.58$ to $11.38 \pm 10.03$ and LVEF improved from $48.40 \pm 13.15 \%$ to $53.37 \pm 12.8 \%$. There was significant improvement of LVEF from acute setting during the next $10-14$ weeks $(p=0.001)$. There was significant lowering of SRS $(P=0.007)$. Perfusion defect size showed significant reduction $(P=0.030)$. Three patients showed worsening in perfusion defect size and in summed score with reduction in LVEF. One of these three patients was 60 year old male with AWMI, who was reperfused 8 hours post AMl and symptom presentation, second one was 40 years old male with AWMI reperfused at 6 hours and the third one was 67 years old male with AWMI reperfused after 7 hours. In these three patients the size of perfusion defect increased from 27 to $30 \%, 25$ to $30 \%$ and 27 to $38 \%$ respectively. In four patients we did not observe any change in parameters. Correlation between perfusion defect and LVEF overall was strong both at baseline studies $(r=-0.705, p<0.001)$ and after 10-18 weeks of revascularization ( $r=-0.766, p<0.001)$ (Fig. 4 and 5$)$. 
Table 5. Summed score, Extent of defect and LVEF at 1-3 days and at 10-14 weeks

\begin{tabular}{|c|c|c|c|c|}
\hline Variables & Acute & After 3 months & $P$ value & Effect size \\
\hline LVEF\% & $48.40 \pm 13.15$ & $53.37 \pm 12.86$ & $0.001^{* *}$ & $0.38(S)$ \\
\hline SUMMED SCORE & $14.31 \pm 10.58$ & $11.38 \pm 10.03$ & $0.007 * \star$ & $0.28(S)$ \\
\hline EXTENT OF DEFECT & $19.76 \pm 12.89$ & $16.79 \pm 12.61$ & $0.030 *$ & $0.23(S)$ \\
\hline
\end{tabular}

*Moderately significant ( $P$ value: $0.01<P \leq 0.05)$; ${ }^{*}$ Strongly significant ( $P$ value: $\left.P \leq 0.01\right)$; Average change in ejection fraction: $5.26 \%$, Average change in summed score: $26 \%$; VEF — left ventricular ejection fraction

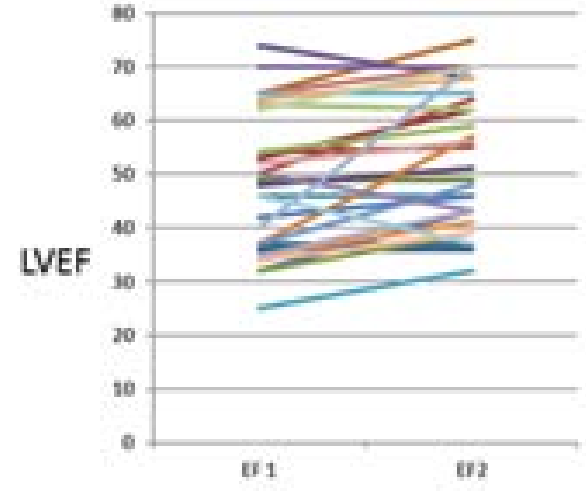

Figure 1. Showing temporal change in LVEF from first MPI to second MPI. EF 1 is at $1-3$ days and EF2 is at $10-14$ weeks. LVEF - left ventricular ejection fraction

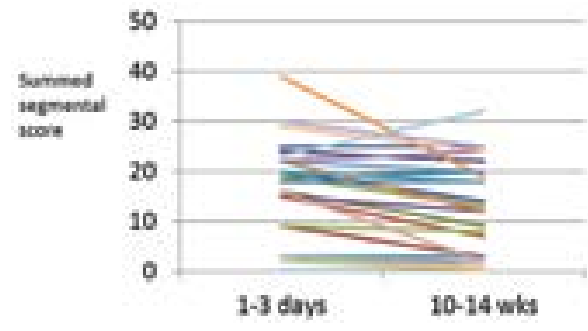

Figure 2. Temporal change in summed segmental score

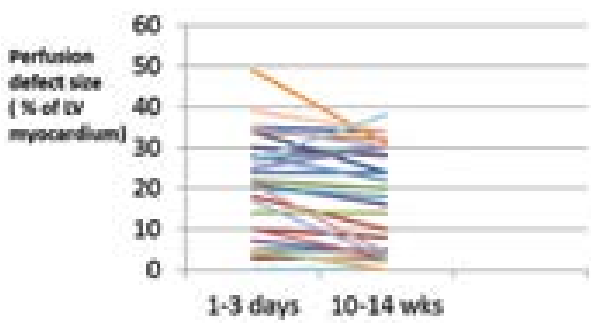

Figure 3. Temporal change in perfusion defect size

\section{Discussion}

Timely reperfusion is the mainstay of treatment of ST segment elevation myocardial infarction (STEMI) [10-12]. The TIMI flow achieved is an important prognostic marker for in-hospital mortality and clinical outcome 6 months post MI [13]. Myocardial perfusion and LVEF may be abnormal despite restoration of TIMI 3 flow

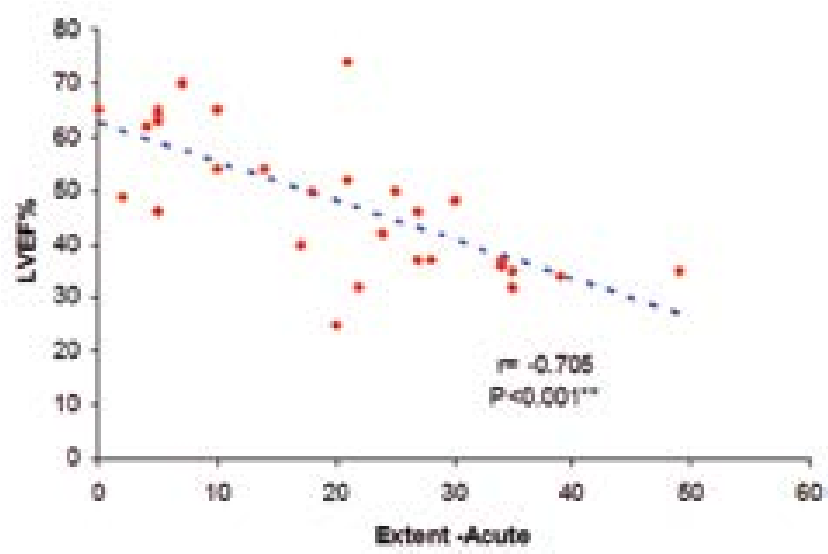

Figure 4. Correlation between LVEF and perfusion defect in the acute setting. LVEF — left ventricular ejection fraction

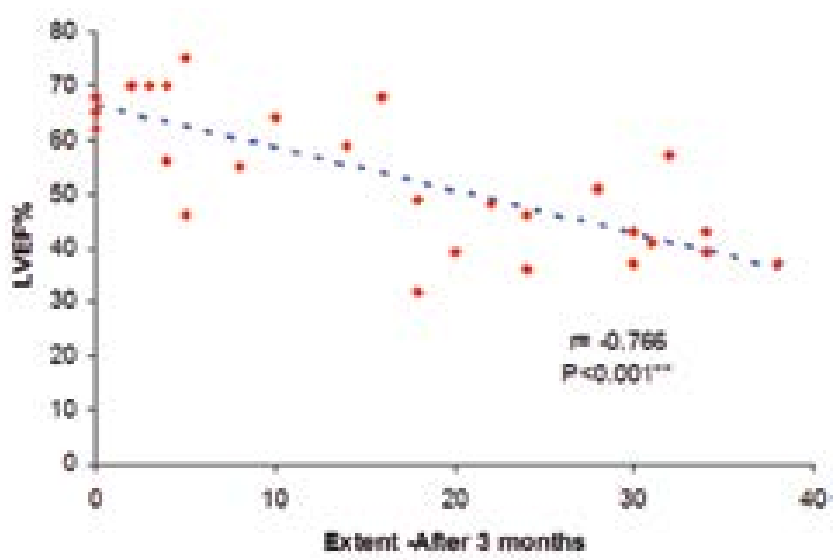

Figure 5. Correlation between LVEF and perfusion defect (extent) after 3 months. LVEF - left ventricular ejection fraction

[14-17]. These two indices (myocardial perfusion defect and LVEF) change with time after reperfusion and both of these are important predictors of mortality $[18,19]$.

The changes in myocardial perfusion and function after successful reperfusion are not predictable and vary from patient to patient. A lot of physiological and pathological factors come into play. There is scanty and variable information available regarding the course of changes in perfusion defect size and LV function after primary angioplasty. There is still search for an ideal reperfusion marker, especially nowadays with improvements in the technique, usage of drug eluting stents and low restenosis rates $[20,21]$. Some earlier studies have revealed that remodeling and changes in LV function continues beyond 6months [22]. Whereas other studies 
have negated this fact and concluded that LVEF does not change after few days to few weeks of reperfusion only the perfusion defect might change [23].

Now it is well known that myocardial stunning in the region of infarction may persist for weeks to months after restoration of blood flow [4]. Although these segments are underfunctioning, they are still viable and well perfused as seen by uptake of Sestamibi/Tetrofosmin. When slowly the cellular function restores, there is further improvement in LVEF. In addition, the presence of hibernating myocardium affects the size of the perfusion defect as detected by Sestamibi scan because Sestamibi uptake is a function of blood flow as well as viability [24]. Hence the under perfused but viable myocardium may not be differentiated from scar. The slow restoration of the microvascular function improves the perfusion gradually and leads to reduction in perfusion defect size as well as restoration of function. Also, there may be an inherent property of infarct to shrink in days to weeks owing to edema resorption and phagocytation of dead myocardial cells in early stage and later collagen production and contraction [25].

Christian et al. in their study of 84 consecutive patients of AMI who were treated with reperfusion therapy, did MPI Sestamibi study in the acute stage and at discharge and radionuclide Ventriculography at discharge and at 6 weeks. They reported that 25\% patients with AMI had stunned myocardium and they had lower LVEF than expected of perfusion defect size at hospital discharge and these patients showed a late increase in LVEF after 6 weeks. They also found out that $18 \%$ of patients had drop in LVEF and they are classified as mismatch-hyperkinetic group in which the myocardium is hyperkinetic initially (outside the infarct zone) and settles down later. They explained it on the basis of compensatory hyperkinesia likely to be due to fluctuations in catecholamine release [26, 27].

Hence there are many factors which affect the progress of perfusion defect size and LVEF after reperfusion therapy in patients of AMI. Understanding the natural course of evolution of size of infarction and LVEF is important. How early can we do MPI study to accurately assess the results of reperfusion and prognosticate the illness was the question we wanted to study. We evaluated the changes in resting MPI at two points of time: 1-3 days' after reperfusion and 10 to 14 weeks after reperfusion. Analysis of LVEF, summed rest score (SRS) and extent of perfusion defect in acute setting and after 10-14 weeks was done. The average acute perfusion defect extent was $19.76 \pm 12.89 \%$ which after 3 months (on second MPI at 10-14 weeks post primary PCl) became $16.79 \pm 12.61 \%$. The score changed from $14.31 \pm 10.58$ to $11.38 \pm 10.03$ and LVEF improved from $48.40 \pm 13.15 \%$ to $53.37 \pm 12.8 \%$. Hence there was significant improvement in LVEF from acute setting to after 10-14 weeks $(p=0.001)$. There was significant lowering of summed rest score $(p=0.007)$. Perfusion defect showed significant reduction $(p=0.030$ ). Three patients showed deterioration in perfusion defect size and in summed score with reduction in LVEF. On detailed analysis, it was evident that these were late presenters. Castro et al. analyzed the perfusion defect, LV function and LV volumes at baseline (preprocedural), 72 hours and 3 months after treatment, and they reported that there were no changes between the baseline studies and performed after 72 hours in LV function. However, a significant increase of LVEF was found 3 months after treatment (baseline LVEF of $40 \pm 13$ at 3 months ( $50 \pm 10 \%$, $p<0.05)$. The perfusion defect size showed significant reduction at 72 hours and further reduced after 3 months. They expressed this as myocardial salvage percentage $(30 \%$ at 72 hours which increased to $65 \%$ at 3 months). Hence, they concluded that the actual favorable effect in LV function and perfusion defect size takes 3 months [21]. Although we did not do the MPI prior to revascularization procedure due to logistic constraints, our findings are similar to the above study. Ottervanger et al. studied changes in LVEF in patients treated with primary angioplasty. LV ejection fraction was measured by radionuclide ventriculography on the 4th day after primary angioplasty and was repeated after 6 months. He found the mean relative improvement in LVEF was 6\% [19]. In our study the mean improvement in LVEF was $5.3 \%$ after 3 months itself. Hence, maximum improvement probably occurs by 3 months itself. Hence, we feel that for accurate estimation of disease status and quantifying results; MPI at 3 months may be preferable.

LVEF has been used as marker for prognostication of MI. Only LVEF being the end point for prognostication has limitations. It is affected by many factors like therapy with Angiotensin converting enzyme (ACE) inhibitors and Beta blockers and there is natural tendency of the LV to improve in high proportion of cases after MI. Hence infarct size is also important parameter to be followed up $[28,29]$. To evaluate both these parameters MPI is the best modality.

In our study correlation between perfusion defect and LVEF was strong both at baseline $(r=-0.705, p<0.001)$ and after $10-18$ weeks $(r=-0.766, p<0.001)$. We found a consistent relation between the size of the perfusion defect and the LVEF, which is like what others have reported [19, 30]. Furthermore, we found the initial perfusion defect correlated to both summed score and LV ejection fraction after 3 months, which might be useful for identifying the patients at risk of LV remodelling. Kaltoft et al. in their study of 19 patients with AMI where they did Tc-99m SESTAMIBI SPECT imaging immediately after revascularization and after 3 months showed that the results of the acute imaging correlated significantly with the final infarct size, LV volume and LV function 3 months later. They concluded that the method holds the potential of risk stratifying patients immediately after revascularization [18]

Halvorsen et al. in their study of 100 consecutive patients who were treated with primary angioplasty for acute ST-elevation myocardial infarction, determined LVEF by radionuclide ventriculography before discharge, after 6 weeks and after 20 months. Infarct size was assessed by technetium 99m-tetrofosmin SPECT at rest at 1 week, after 6 weeks and after 20 months. Mean LVEF was $56 \%$ at discharge, $55 \%$ after 6 weeks and $57 \%$ after 20 months of follow-up. After 1 week, a mean perfusion defect of $19 \%$ was measured by SPECT. After 6 weeks and 20 months of follow-up, the mean perfusion defects extent were reduced to $14 \%(p<0.001)$ and $15 \%$, respectively. Hence, they concluded that LVEF does not change after 1 week of revascularization procedure but perfusion defect changes over long time [23]. However most of the other studies have different results and LVEF does change over time. The changes in LVEF we found after 3 months are similar to earlier studies [21,31] and also to studies using follow up at 6 months to 1 year $[19,32-34]$.

\section{Conclusion}

This study of 30 primary angioplasty patients adds further information to the pre-existing limited knowledge about early 
changes occurring in the LV myocardium post primary angioplasty. It shows clearly that the perfusion defect size and LVEF measured 1-3 days after revascularization in patients of AMI are not accurate depiction of the results of the procedure. We feel that 3 months is a good enough time to accurately assess the success of the procedure.

\section{Limitations}

1. We did the first MPI 1-3 days after the primary angioplasty, if some improvement occurred in that period then we might be underestimating the actual benefit of revascularization.

2. We have not followed up 4 months and beyond hence cannot comment on prognostic importance.

3. Sample size was restricted to study duration.

4. There are so many other factors e.g. drugs received by the patient, which have impact on the recovery of LVEF and remodelling process which we have not studied. Treatment was not randomized; all the patients were treated by the decision of the cardiologist.

5. We adopted the 20 segment scoring method on polar maps due to lack of availability of 17 segment scoring software in our system. The 17 segment model is recommended as it provides best agreement with other imaging modalities and anatomical data [35].

\section{References}

1. Baks T, van Geuns RJ, Biagini E, et al. Effects of primary angioplasty for acute myocardial infarction on early and late infarct size and left ventricular wall characteristics. J Am Coll Cardiol. 2006; 47(1): 40-44, doi: 10.1016/j. jacc.2005.09.008, indexed in Pubmed: 16386662.

2. Conti CR. The stunned and hibernating myocardium: a brief review. Clin Cardiol. 1991; 14(9): 708-712, doi: 10.1002/clc.4960140903, indexed in Pubmed: 1742904

3. Sawyer DB, Loscalzo J. Myocardial hibernation: restorative or preterminal sleep? Circulation. 2002; 105(13): 1517-1519, doi: 10.1161/01. cir.0000014689.12415.89, indexed in Pubmed: 11927510.

4. Uren N, Crake T, Lefroy D, et al. Delayed recovery of coronary resistive vessel function after coronary angioplasty. J Am Coll Cardiol. 1993; 21(3): 612-621, doi: 10.1016/0735-1097(93)90092-f, indexed in Pubmed: 8436742.

5. Cobb FR, Williams RS, McEwan P, et al. Effects of exercise training on ventricular function in patients with recent myocardial infarction. Circulation. 1982; 66(1): 100-108, doi: 10.1161/01.cir.66.1.100, indexed in Pubmed: 7083497.

6. Hung J, Gordon EP, Houston N, et al. Changes in rest and exercise myocardial perfusion and left ventricular function 3 to 26 weeks after clinically uncomplicated acute myocardial infarction: effects of exercise training. Am J Cardiol. 1984; 54(8): 943-950, doi: 10.1016/s0002-9149(84)80123-x, indexed in Pubmed: 6496357

7. Silberberg J, Haichin R, Stewart S, et al. Long-term stepwise sustained improvement in left ventricular ejection fraction after myocardial infarction. Am Heart J. 1989; 117(3): 532-537, doi: 10.1016/0002-8703(89)90725-4, indexed in Pubmed: 2919532

8. Levine GN, Bates ER, Blankenship JC, et al. ACCF/AHA/SCAI Guideline for Percutaneous Coronary Intervention: executive summary: a report of the American College of Cardiology Foundation/American Heart Association Task Force on Practice Guidelines and the Society for Cardiovascular Angiography and Interventions. Circulation. 2011; 124(23): 574-651, doi: 10.1161/cir.0b013e31823a5596, indexed in Pubmed: 22064598.

9. Berman DS, Kang X, Van Train KF, et al. Comparative prognostic value of automatic quantitative analysis versus semiquantitative visual analysis of exercise myocardial perfusion single-photon emission computed tomography. J Am Coll Cardiol. 1998; 32(7): 1987-1995, doi: 10.1016/s07351097(98)00501-4, indexed in Pubmed: 9857883.

10. Boersma $E$, Mercado $N$, Poldermans $D$, et al. Acute myocardial infarction. Lancet. 2003; 361(9360): 847-858, doi: 10.1016/s0140-6736(03)12712-2, indexed in Pubmed: 12642064.

11. Kurowski V, Giannitsis E, Killermann D, et al. The effects of facilitated primary $\mathrm{PCl}$ by guide wire on procedural and clinical outcomes in acute ST-segment elevation myocardial infarction. Clin Res Cardiol. 2008; 96(8): 557-565.

12. Ribichini F, Ferrero V, Wijns W. Reperfusion treatment of ST-elevation acute myocardial infarction. Prog Cardiovasc Dis. 2004; 47(2): 131-157, doi: 10.1016/j.pcad.2004.07.007, indexed in Pubmed: 15586353.

13. Ito $\mathrm{H}$, Okamura A, Iwakura $\mathrm{K}$, et al. Myocardial Perfusion Patterns Related to Thrombolysis in Myocardial Infarction Perfusion Grades After Coronary Angioplasty in Patients With Acute Anterior Wall Myocardial Infarction. Circulation. 1996; 93(11): 1993-1999, doi: 10.1161/01.cir.93.11.1993, indexed in Pubmed: 8640973.

14. Ito $\mathrm{H}$, Tomooka $\mathrm{T}$, Sakai $\mathrm{N}$, et al. Lack of myocardial perfusion immediately after successful thrombolysis. A predictor of poor recovery of left ventricular function in anterior myocardial infarction. Circulation. 1992; 85(5): 1699-1705, doi: 10.1161/01.cir.85.5.1699, indexed in Pubmed: 1572028.

15. Wu KC, Zerhouni EA, Judd RM, et al. Prognostic Significance of Microvascular Obstruction by Magnetic Resonance Imaging in Patients With Acute Myocardial Infarction. Circulation. 1998; 97(8): 765-772, doi: 10.1161/01. cir.97.8.765, indexed in Pubmed: 9498540.

16. Roe M, Ohman E, Maas A, et al. Shifting the open-artery hypothesis downstream: the quest for optimal reperfusion. J Am Coll Cardiol. 2001; 37(1): 9-18, doi: 10.1016/s0735-1097(00)01101-3, indexed in Pubmed: 11153779.

17. Piana RN, Paik GY, Moscucci M, et al. Incidence and treatment of 'no-reflow' after percutaneous coronary intervention. Circulation. 1994; 89(6): 2514-2518, doi: 10.1161/01 .cir.89.6.2514, indexed in Pubmed: 8205658.

18. Kaltoft A, Bøttcher M, Sand N, et al. Electrocardiographic Gated ${ }^{99 m} \mathrm{mc}-$ Sestamibi SPECT Immediately after Primary Percutaneous Coronary Intervention Characterizes Reperfusion Success. Cardiology. 2003; 99(4): 198-204, doi: 10.1159/000071249.

19. Ottervanger JP, van't Hof A, Reiffers $S$, et al. Long-term recovery of left ventricular function after primary angioplasty for acute myocardial infarction. Eur Heart J. 2001; 22(9): 785-790, doi: 10.1053/euhj.2000.2316, indexed in Pubmed: 11350111.

20. Gibbons RJ, Christian T, Hopfenspirger M, et al. Myocardium at risk and infarct size after thrombolytic therapy for acute myocardial infarction: Implications for the design of randomized trials of acute intervention. J Am Coll Cardiol. 1994; 24(3): 616-623, doi: 10.1016/0735-1097(94)90005-1, indexed in Pubmed: 8077529.

21. Castro PF, Corbalan R, Baeza R, et al. Effect of primary coronary angioplasty on left ventricular function and myocardial perfusion as determined by Tc-99m sestamibi scintigraphy. Am J Cardiol. 2001; 87(10): 1181-1184, doi: 10.1016/s0002-9149(01)01490-4, indexed in Pubmed: 11356394.

22. Gaudron P, Eilles $C$, Ertl $G$, et al. Compensatory and noncompensatory left ventricular dilatation after myocardial infarction: Time course and hemodynamic consequences at rest and during exercise. Am Heart J. 1992; 123(2): 377-385, doi: 10.1016/0002-8703(92)90649-g, indexed in Pubmed: 1736573.

23. Halvorsen S, Müller C, Bendz B, et al. Left Ventricular Function and Infarct Size 20 Months after Primary Angioplasty for Acute Myocardial Infarction. Scand Cardiovasc J. 2001; 35(6): 379-384, doi: 10.1080/14017430152754862, indexed in Pubmed: 11837517.

24. Sawada SG, Allman KC, Muzik O, et al. Positron emission tomography detects evidence of viability in rest technetium-99m sestamibi defects. J Am Coll Cardiol. 1994; 23(1): 92-98, doi: 10.1016/0735-1097(94)90506-1, indexed in Pubmed: 8277101.

25. Reimer KA, Lowe JE, Rasmussen MM, et al. The wavefront phenomenon of ischemic cell death. 1. Myocardial infarct size vs duration of coronary 
occlusion in dogs. Circulation. 1977; 56(5): 786-794, doi: 10.1161/01. cir.56.5.786, indexed in Pubmed: 912839.

26. Christian TF, Gitter MJ, Miller TD, et al. Prospective Identification of Myocardial Stunning Using Technetium-99m Sestamibi-Based Measurements of Infarct Size. J Am Coll Cardiol. 1997; 30(7): 1633-1640, doi: 10.1016/s07351097(97)00409-9, indexed in Pubmed: 9385887.

27. Sheehan F, Mathey D, Schofer J, et al. Effect of interventions in salvaging left ventricular function in acute myocardial infarction: A study of intracoronary streptokinase. Am J Cardiol. 1983; 52(5): 431-438, doi: 10.1016/00029149(83)90002-4.

28. Hill JM, Bartunek J. The End of Granulocyte Colony-Stimulating Factor in Acute Myocardial Infarction?: Reaping the Benefits Beyond Cytokine Mobilization. Circulation. 2006; 113(16): 1926-1928, doi: 10.1161/circulationaha.106.623777, indexed in Pubmed: 16636185.

29. Zohlnhöfer D, Ott I, Mehilli J, et al. REVIVAL-2 Investigators. Stem cell mobilization by granulocyte colony-stimulating factor in patients with acute myocardial infarction: a randomized controlled trial. JAMA. 2006; 295(9): 1003-1010, doi: 10.1001/jama.295.9.1003, indexed in Pubmed: 16507801.

30. Chareonthaitawee P, Christian T, Hirose K, et al. Relation of initial infarct size to extent of left ventricular remodeling in the year after acute myocardial infarction. J Am Coll Cardiol. 1995; 25(3): 567-573, doi: 10.1016/07351097(94)00431-0, indexed in Pubmed: 7860898.
31. Kurihara H, Nakamura S, Takehana K, et al. Scintigraphic prediction of left ventricular functional recovery early after primary coronary angioplasty using single-injection quantitative electrocardiographic gated SPECT. Nucl Med Commun. 2005; 26(6): 505-511, doi: 10.1097/00006231-200506000-00005, indexed in Pubmed: 15891593

32. Candell-Riera J, Pereztol-Valdés O, Oller-Martínez G, et al. [Evolution of systolic function and myocardial perfusion, evaluated by gated-SPECT, in the first year after acute myocardial infarction]. Rev Esp Cardiol. 2003; 56(5): 438-444, indexed in Pubmed: 12737780.

33. Ndrepepa G, Mehilli J, Martinoff S, et al. Evolution of Left Ventricular Ejection Fraction and its Relationship to Infarct Size After Acute Myocardial Infarction. J Am Coll Cardiol. 2007; 50(2): 149-156, doi: 10.1016/j.jacc.2007.03.034, indexed in Pubmed: 17616299.

34. Araszkiewicz A, Lesiak M, Grajek S, et al. Effect of microvascular reperfusion on prognosis and left ventricular function in anterior wall myocardial infarction treated with primary angioplasty. Int $\mathrm{J}$ Cardiol. 2007; 114: 183-187.

35. Cerqueira MD, Weissman NJ, Dilsizian V, et al. Standardized myocardial segmentation and nomenclature for tomographic imaging of the heart. A statement for healthcare professionals from the Cardiac Imaging Committee of the Council on Clinical Cardiology of the American Heart Association. Circulation. 2002; 105(4): 539-542, indexed in Pubmed: 11815441. 